\title{
Two outbreaks of diarrhoea in nurseries in Norway after farm visits, April to May 2009
}

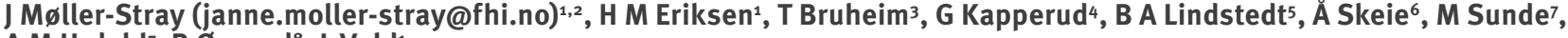 \\ A M Urdahl', B Øygard ${ }^{8}$, L Vold ${ }^{1}$ \\ 1. Department of Infectious Disease Epidemiology, Norwegian Institute of Public Health, Oslo, Norway \\ 2. Norwegian Field Epidemiology Training Programme, European Centre for Disease Prevention and Control, Stockholm, Sweden \\ 3. Norwegian Veterinary Institute, Trondheim, Norway \\ 4. Division of infectious disease control, The Norwegian Institute of Public Health, Oslo, Norway \\ 5. Department of Foodborne Infections, The Norwegian Institute of Public Health, Oslo, Norway \\ 6. The Local office for Haugalandet, The Norwegian Food Safety Authority, Haugesund, Norway \\ 7. Norwegian Veterinary Institute, Oslo, Norway \\ 8. The municipality of Sauda, Sauda, Norway
}

Citation style for this article:

Møller-Stray J, Eriksen HM, Bruheim T, Kapperud G, Lindstedt BA, Skeie Å, Sunde M, Urdahl AM, Øygard B, Vold L. Two outbreaks of diarrhoea in nurseries in Norway after farm visits, April to May 2009. Euro Surveill. 2012;17(47):pii=20321. Available online: http://www.eurosurveillance.org/ViewArticle.

aspx?Articleld $=20321$

During a 2009 nationwide outbreak of sorbitolfermenting Escherichia coli $0_{157}$ in Norway, the Norwegian Institute of Public Health was notified of diarrhoea outbreaks in two nurseries. A link to the nationwide outbreak was suspected and investigated, including retrospective cohort studies. Both nurseries had recently visited farms. Faecal specimens were obtained from symptomatic children as well as from the farm animals and tested for Campylobacter, Salmonella, Yersinia, Shigella and pathogenic E. coli, and isolates were further characterised. Nursery $A$ had 12 symptomatic children, and we found the same strain of $C$. jejuni in faeces from children and lambs. Nursery B had nine symptomatic children, including one child with bloody diarrhoea carrying enterohaemorrhagic E. coli (EHEC) 026. EHEC 026 with a similar multiple-locus variable number tandem repeat analysis (MLVA)-profile was found in sheep. Five children had enteropathogenic E. coli (EPEC) 076. Animals were not tested for EPEC 076 . We found no significant association between illness and risk factors for either nursery. The isolated pathogens differed from the one involved in the nationwide outbreak. In each nursery outbreak, the pathogens isolated from children matched those found in farm animals, implicating animal faeces as the source. Hygiene messages are important to prevent similar outbreaks.

\section{Introduction}

There are several reports from around the world of sporadic cases as well as outbreaks of zoonoses, especially among children, after farm visits $[1,2]$. The most commonly described pathogens in these incidents are different strains of Escherichia coli [3-12], but other pathogens including Campylobacter are reported as well $[1,13]$.

Enterohaemorrhagic E. coli (EHEC) are known to cause infections that can lead to serious complications such as haemolytic-uraemic syndrome (HUS), especially in children, immuno-compromised persons and the elderly. The proportion of patients diagnosed with EHEC who develop HUS is around 10\% [14,15], but varies by host factors and type of EHEC. In Europe, more than $50 \%$ of patients diagnosed with sorbitol-fermenting (SF) EHEC $0_{157}$ (SF 0157) develop HUS [14,16].

In the spring of 2009 there was a national outbreak of SF EHEC 0157 in Norway, affecting 13 children, including nine HUS cases of whom one died $[17,18]$. This outbreak attracted a lot of media attention, reinforced by the public's memory of the first large EHEC outbreak in Norway in 2006, that affected 17 children including 10 HUS cases of whom one died [19].

In May 2009, as the Norwegian Institute of Public Health (NIPH) was investigating the national outbreak of EHEC SF 0157, additionally the chief medical officers of two distinct Norwegian municipalities each notified an outbreak of diarrhoea in a nursery in their respective municipalities: On 12 May we received the notification from Nursery A in Rogaland County in south-western Norway, while on 14 May we received the notification from Nursery $B$ in Akershus County in the eastern part of Norway. A stool specimen from a child with bloody diarrhoea from Nursery B was positive for stx2, a gene encoding one of the EHEC toxins. We also had information that children attending both nurseries had participated in farm visits. During the visits children had cuddled the farm animals. Nurseries in Norway function as pedagogical daycare facilities for children under the age of six years.

We initiated investigations of the two nursery outbreaks. Our aims were to decide whether they were associated with the concomitant national outbreak of EHEC SF 0157, and to identify the source or sources of infection in order to stop the current outbreaks and 
prevent similar outbreaks in the future. In order to reach our aims, we wanted to test the following hypotheses: (i) The pathogen causing the nursery outbreaks was EHEC SF 0157. (ii) The nursery children who participated in the farm visit had a higher risk of becoming ill than those who did not.

Coincidentally with initiating the investigations we took preliminary measures to control the outbreaks by excluding ill children from attending the nurseries, as recommended in the NIPH guidelines for infection control in nurseries [20].

\section{Materials and methods}

\section{Epidemiological investigation}

The investigations were conducted by the NIPH in cooperation with the chief medical officers in the affected municipalities and the Norwegian Food Safety Authority (NFSA). We performed a retrospective cohort study in each nursery. We collected information on each child's nursery attendance, travel history and participation in gatherings preceding the outbreaks, symptoms of disease (if any), food consumption, participation in the farm visit, and animal contact at the farm. Questions about food consumption were based on menu lists of food and beverages served in the nurseries, collected by the local NFSA offices.

We collected this information from the nursery staff, using detailed questionnaires based on the NIPH's standardised outbreak questionnaire [21], adjusted for the respective nurseries. For Nursery $A$ the farm visit took place on 5 May, the questionnaires were filled out on 15 May, and the questions covered the period from 4 May. The time frame for travel history was 1-7 May. The question about gatherings was not included in the questionnaire for each child, but the nursery staff were asked if they were aware of anyone in the nursery group participating in any gatherings during the week before the outbreak. For Nursery B the farm visit took place on 29 April, the questionnaires were filled out on 19 May, and the questions covered the period from 27 April. The time frame for travel history and gatherings was 27-30 April.

We collected information on gastrointestinal illness for each child in the query period. For those who were ill, we asked about specific symptoms including diarrhoea, vomiting, nausea, abdominal pain, fever, bloody stools and joint pain.

\section{Case definitions}

We defined a case for Outbreak $A$ as a child that attended Nursery A in April and May 2009 and a case for Outbreak B as a child that attended Nursery B in the period from April 29 to May 19, with the following additional criteria: Suspected cases were those who showed symptoms of gastroenteritis in the query period (general gastroenteritis, vomiting and/or diarrhoea). Because the microbiological results later indicated that the outbreak in Nursery A was caused by Campylobacter jejuni and the outbreak in Nursery B by $E$. coli, the definition for confirmed cases was chosen accordingly as: those who tested positive for $C$. jejuni in Nursery $A$ and those who tested positive for pathogenic $E$. coli in Nursery $B$.

\section{Statistical analyses}

We conducted descriptive statistics and univariate analyses using Stata (version 11). In the univariate analyses we calculated the relative risk (RR) with $95 \%$ confidence intervals $(\mathrm{Cl})$ for association between illness and different risk factor exposures such as participation at farm visit, sex and age of the child as well as consumption of diverse food items and beverages. We performed the analyses both for confirmed cases only, and for suspected and confirmed cases combined.

\section{Microbiological investigations}

\section{Human specimens}

We aimed to collect faecal specimens from all children with symptoms. The initial analyses were performed at the regional medical microbiological laboratories, and included testing for Campylobacter, Salmonella, Yersinia, Shigella and pathogenic E. coli according to the standard protocols of the respective laboratories. The specimens from the children in Nursery A were also tested for rotavirus and adenovirus by immunochromatography [22]. The specimens from the children in Nursery B were not tested for viruses after we had identified pathogenic $E$. coli as the pathogen of the outbreak in this nursery. For the bacterial isolates that we suspected as possible causative infecting agents, we conducted further verification and typing (described below) at the reference laboratory at the NIPH.

From children who tested positive for pathogenic $E$. coli, we collected specimens repeatedly, until we considered them not to be contagious anymore and hence allowed them to attend nursery again. According to NIPH guidelines [20], for EHEC this requires five consecutive negative tests of faecal specimens collected a minimum of 24 hours apart.

\section{Animal specimens}

The district offices of the NFSA collected faecal specimens from animals and transported them at ambient temperature to the laboratory at the Norwegian Veterinary Institute (NVI) for examination within 24 hours.

From the farm visited by Nursery A, specimens from six lambs were collected and tested for Campylobacter according to an ISO-method [23]. In addition we evaluated the bacterial flora by plating out on non-selective media, and performed standard bacteriological testing. From the farm visited by Nursery B, we collected 36 specimens from sheep and 17 from cattle (one test per animal), and tested them individually for $E$. coli 
026 by automated immunogenic separation (AIMS) as described previously [24]. We did not perform standard bacteriology on these animal specimens, and as adequate methods were unavailable we did not analyse them for $E$. coli 076 .

Typing and comparisons of human and animal isolates At the DNA-analysis laboratory of the Department of Foodborne Infections at the NIPH, we typed and compared all animal isolates with the human isolates from the corresponding outbreak. We ascertained the DNA profiles of $C$. jejuni isolates by combining three different methods: clustered regularly interspaced short palindromic repeat (CRISPR) polymorphism, single nucleotide polymorphism (SNP) typing and binary gene typing (BGT) [25-28]. We assessed the DNA profiles of $E$. coli by multi-locus variable number of tandem repeats analysis (MLVA). We implemented a generic E. coli MLVA assay for all non-0157 isolates as detailed previously $[29,30]$. For the $E$. coli 026 isolates, we examined virulence, including detection of eae and the stx genes, as described elsewhere [31,32].

\section{Environmental investigations}

The district offices of the NFSA inspected the farms and the nurseries and collected specimens of food and drinks from Nursery A on 13 May. We also asked for water specimens from both nurseries. On 15 May the district office of the NFSA inspected and collected specimens of food and garbage from the kitchen in the home of the child with bloody diarrhoea in Nursery B.

Nursery A brought its own water from a water processing plant approved by the NFSA to the farm visit. Nonetheless, on 26 May we collected a water specimen from the farm, which was served by groundwater from a well. Eurofins Environment Testing Norway AS, Stavanger, analysed this specimen for total bacterial count at $22^{\circ} \mathrm{C}$, coliform bacteria, generic $E$. coli, Campylobacter, and Clostridium perfringens.

We also collected faecal specimens from the floor of two lamb pens at the farm visited by Nursery A. We investigated these specimens in the same way as the faecal specimens taken from the animals.

\section{Results}

\section{Descriptive epidemiology}

\section{Nursery A}

Of the 24 children attending Nursery A, 12 met the definition of a suspected case (attack rate (AR): $50 \%$ ). The suspected cases were all between three and six years of age with median age four years, as for the nursery group in general. Ten of the suspected cases were girls. The first child became ill on 7 May. The 12 suspected cases included one child that became ill on 16 May, the day after the end of the query period. We included the information on this child's disease upon later notification from the chief medical officer of the

\section{FIGURE 1}

Number of suspected cases in Nursery A by date of onset of disease, Norway, May $2009(\mathrm{n}=11)$

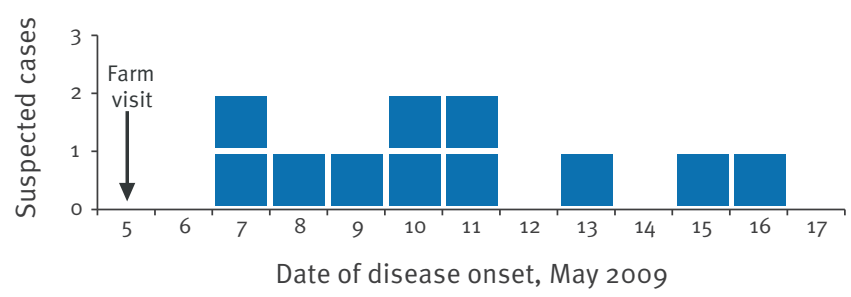

Note: One of the 12 suspected cases is not shown as illness onset date was not available.

municipality. Of the 24 children in the nursery, three did not participate in the farm visit. One of these had symptoms defining her as one of the 12 suspected cases (date of onset 11 May).

We aimed to exclude all children with symptoms of gastroenteritis from nursery attendance until $48 \mathrm{~h}$ after cease of symptoms, as recommended by the NIPH guidelines for infection control in nurseries [20].

Nursery B

Of the 16 children attending Nursery B, seven met the definition of a suspected case (AR: $44 \%$ ). The suspected cases were all between one and five years of age, as for the nursery in general. The median age for the suspected cases was two years, compared with three years for the nursery in general. Three of the suspected cases were girls. The first child became ill on 2 May, while the latest reported illness onset was on 8 May. One of the 16 children did not participate in the farm visit. This child did not become ill.

\section{FIGURE 2}

Number of suspected cases in Nursery B by date of onset of disease, Norway, April-May 2009 ( $n=7$ )

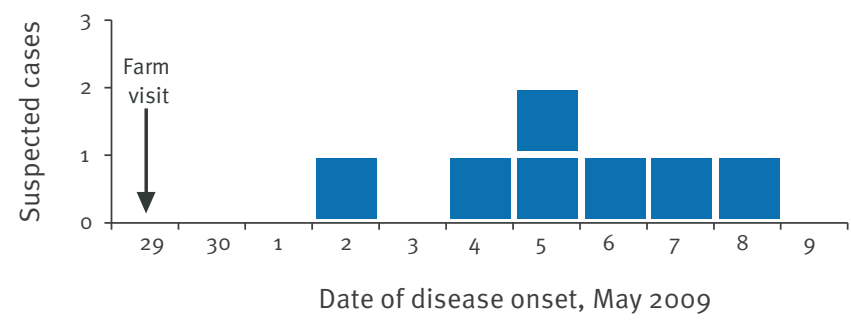


Microbiological results

Nursery A

We sampled and analysed four of the 12 suspected cases. These four specimens all yielded $C$. jejuni with identical DNA-profiles, and no other pathogens.

Specimens from four of the lambs on the visited farm were positive for $C$. jejuni with the same DNA-profile as the human isolates. We detected no other pathogens in the specimens from the lambs.

Nursery B

We analysed specimens from the seven suspected cases in Nursery B. In addition, two further children were sampled, who are not considered in the epidemiological analysis above because they had more general symptoms not included in the final suspected case definition. From specimens of the suspected case with bloody diarrhoea, we isolated EHEC 026, stx1 negative, stx2a positive and eae positive. In addition we identified atypical enteropathogenic $E$. coli (aEPEC) 076, all with an identical MLVA-profile, from the specimens of a further five children, including one who did not fulfill the suspected case definition.

We aimed to exclude all children with faecal specimens positive of EHEC or EPEC from nursery attendance until they had repeated negative faecal specimens, as recommended for EHEC cases by the NIPH guidelines for infection control in nurseries [20].

We identified EHEC 026, with the same virulence genes as the human isolate, from two specimens of cattle and four specimens of sheep on the farm visited by Nursery B. The MLVA-profiles of the human and animal isolates were almost identical, differing in one locus only.

\section{Environmental results}

Nursery A had visited a farm with about 290 sheep and 430 lambs. The children were allowed to enter lamb pens. There was a sink in the barn, but the children did not use it to wash their hands. The staff from Nursery $A$ brought hand disinfection that the children used prior to their meal. They ate outside in the yard sitting on the ground on seating pads. The analyses of the water samples from this farm did not yield positive results. Faecal specimens from the floor of the lamb pens tested positive for $C$. jejuni.

Nursery B had visited a farm with around 60 cattle and 90 sheep. The children had close contact with cows and lambs in the barn and did not wash hands before their meal, which they ate outside in the yard. The water supply both in the nursery and at the farm was a water processing plant approved by the NFSA, with no reports from other recipients indicating contamination of the water. Therefore the local NFSA office regarded the water supply to be of good quality and did not collect any water specimens.

As the microbiological results incriminated farm animals as the source of infection in both outbreaks, we did not analyse the food specimens taken from Nursery $A$, or the food and garbage specimens taken from the kitchen in the home of the child with bloody diarrhoea and EHEC in Nursery B.

\section{Analytical epidemiology}

Nursery A

In total we examined 69 risk factors. By univariate analysis we found that children who ate carrots during the farm visit were more likely to become ill (RR: 2.1; $95 \% \mathrm{Cl}: 1.4-3.2)$, but it has to be noted that this result is based on a single child who ate carrots. We found no other exposure significantly associated with disease. Table 1 shows examples of the risk factors examined for nursery $A$ and their association with being a case (suspected or confirmed).

\section{Nursery B}

In total we examined 55 risk factors. By univariate analysis we found no exposure among the children increasing the risk of becoming ill. Table 2 shows examples of the risk factors examined for nursery $B$ and their association with being a case (suspected or confirmed).

The exposures shown in Table 1 and Table 2 are chosen to illustrate the different categories of risk factors

TABLE 1

Selected results from univariate analysis for Nursery A, Norway, May 2009 ( $n=24)$

\begin{tabular}{|c|c|c|c|c|c|c|c|}
\hline \multirow{2}{*}{\multicolumn{2}{|c|}{ Exposure }} & \multicolumn{2}{|c|}{ Exposed } & \multicolumn{2}{|c|}{ Unexposed } & \multirow{2}{*}{ Risk ratio } & \multirow{2}{*}{$\begin{array}{c}95 \% \text { Confidence } \\
\text { interval }\end{array}$} \\
\hline & & Cases/total & $\%$ & Cases/total & $\%$ & & \\
\hline \multirow{4}{*}{ Farm visit 5 May } & Participation & $11 / 21$ & 52 & $1 / 3$ & 33 & 1.6 & $0.30-8.2$ \\
\hline & Close contact with lambs & $11 / 21$ & 52 & $1 / 3$ & 33 & 1.6 & $0.30-8.2$ \\
\hline & Eating carrots & $1 / 1$ & 100 & $11 / 23$ & 48 & 2.1 & $1.4-3.2$ \\
\hline & Eating fish cakes & $11 / 21$ & 52 & $1 / 3$ & 33 & 1.6 & $0.30-8.2$ \\
\hline \multirow{3}{*}{$\begin{array}{c}\text { Food and beverages } \\
\text { consumed in the nursery } 4-7 \\
\text { May }\end{array}$} & Mutton sausage & $12 / 23$ & 52 & $0 / 1$ & 0 & - & - \\
\hline & Cucumber & $12 / 23$ & 52 & $0 / 1$ & 0 & - & - \\
\hline & Tap water & $12 / 23$ & 52 & $0 / 1$ & 0 & - & - \\
\hline
\end{tabular}


Selected results from univariate analysis for Nursery B, Norway, April-May 2009 (n=16)

\begin{tabular}{|c|c|c|c|c|c|c|c|}
\hline \multirow{2}{*}{\multicolumn{2}{|c|}{ Exposure }} & \multicolumn{2}{|c|}{ Exposed } & \multicolumn{2}{|c|}{ Unexposed } & \multirow{2}{*}{ Risk ratio } & \multirow{2}{*}{$\begin{array}{c}95 \% \text { Confidence } \\
\text { interval }\end{array}$} \\
\hline & & Cases/total & $\%$ & Cases/total & $\%$ & & \\
\hline \multirow{2}{*}{ Farm visit 29 April } & Participation & $8 / 15$ & 53 & $0 / 1$ & 0 & - & - \\
\hline & Eating grilled minced steaks & $8 / 15$ & 53 & $0 / 1$ & 0 & - & - \\
\hline \multirow{7}{*}{$\begin{array}{l}\text { Food and beverages } \\
\text { consumed in the nursery } \\
27-30 \text { April }\end{array}$} & Honey dew melon & $8 / 16$ & 50 & $0 / 0$ & 0 & - & - \\
\hline & Saveloy & $0 / 0$ & 0 & $8 / 16$ & 50 & - & - \\
\hline & Liver paste & $6 / 14$ & 43 & $2 / 2$ & 100 & 0.43 & $0.23-0.78$ \\
\hline & Mayonnaise & $8 / 16$ & 50 & $0 / 0$ & 0 & - & - \\
\hline & Margarine & $4 / 12$ & 33 & $4 / 4$ & 100 & 0.33 & $0.15-0.74$ \\
\hline & Gherkin & $6 / 11$ & 55 & $2 / 5$ & 40 & 1.4 & $0.41-4.5$ \\
\hline & Tap water & $8 / 16$ & 50 & $0 / 0$ & 0 & - & - \\
\hline
\end{tabular}

examined. Some were included because they had been pointed out as sources of earlier outbreaks in Norway (for instance mutton sausage [19]) or abroad.

Overall, the staff in both nurseries had given very similar answers on the questionnaires for all children. As univariate analysis did not yield any positive associations between exposures and illness, and as the number of subjects was low, we considered multivariate analysis not appropriate.

\section{Discussion}

We found that the causative pathogens of the outbreaks were $C$. jejuni in Nursery A, and E. coli 026 and 076 in Nursery B. Thus, we excluded an association with the concomitant national outbreak of $E$. coli SF $0_{157}$.

In each outbreak, we found the same pathogens in faecal specimens from farm animals and from the sick children, implicating the animals as source of the outbreaks, directly or indirectly. The association between illness and eating carrots at the farm visited by Nursery A could only explain one of the 12 cases, and is therefore not plausible as the source of the outbreak.

Earlier publications of outbreaks in Norway due to transmission of zoonoses by animal contact are scarce. However, in 2005 a small outbreak of cryptosporidiosis among students and workers at a farm used for training by the Norwegian School of Veterinary Science was traced to contact with calves [33]. Two other outbreaks of cryptosporidiosis, which occurred in March 2009 and March 2012 among schoolchildren staying in a wildlife reserve, have also been attributed to animal contact $[34,35]$. In addition, animals were discussed as the cause of an outbreak of $E$. coli $\mathrm{O}_{145}$ in a third nursery [36] in September and October 2009. Generally, animal health in Norway has been regarded as good for many years. For example, the national surveillance programme did not detect any Salmonella among domestic animals in 2009 [37]. In contrast, a recent study identified Norwegian sheep flocks as an important reservoir for potentially human-pathogenic E. coli 026 $[31,38]$. Our findings are especially relevant in light of the popularity of visiting farms with children; similar outbreaks might occur again.

It is possible that some of the sick children were secondary cases who acquired the infection from nursery mates. Such secondary transmission of zoonotic agents has also been described after visits to a petting zoo in Canada [9] and is likely in a nursery environment due to the difficulty of ensuring good hand hygiene among young children. The incubation period of campylobacteriosis ranges between one and 10 days [39], indicating secondary transmission for the child in Nursery A that became ill on 16 May. The incubation period of EHEC ranges between two and 10 days, but is probably shorter for EPEC [40], not excluding the possibility of secondary transmission for the children in Nursery B with later disease onset. Both nurseries aimed to exclude children from the nursery while they were symptomatic, but possible failure to achieve this completely could explain secondary transmission.

In two earlier campylobacteriosis outbreaks related to farm visits, the reported ARs for Campylobacter ranged from $0.5 \%$ [1] to $53 \%$ [13], whereas the AR in the outbreak in Nursery A was $50 \%$. In previously described outbreaks of pathogenic $E$. coli infection after farm visits, the ARs ranged from $0.06 \%$ to $18 \%[8,10,12]$, whereas the AR in the outbreak in Nursery $B$ was $44 \%$. The AR depends on the dose of ingested organisms, but for both pathogens the infectious dose is low $[39,40]$. The fact that the children in Nursery B did not wash their hands after close animal contact and before their meal, suggests that many of the children could have ingested an infective dose of the bacteria. This can explain the high AR seen in this outbreak compared with previously described farm-related outbreaks of pathogenic $E$. coli. However, ARs are subject to substantial variation in small cohorts and should be interpreted with caution. 


\section{Limitations}

The small number of affected children hampered the epidemiological investigations. For example, we could not assess the risk ratio of participating in the farm visit, since almost all children participated. It is possible that we could have obtained more conclusive indications of appropriate prevention measures if we had included more detailed questions about the children's behavioural pattern on the farm, as has been described in a Swiss study [41].

Recall problems probably influenced the nursery personnel's answers to the questionnaires, reflected by the similarity between their answers for the different children in each nursery. It is conceivable that the nursery personnel had problems remembering details about food consumption and behaviour of each child. A possible differential recall of exposures by case status is also understandable.

For Nursery A we applied a combined method for DNA typing of $C$. jejuni that is as yet unpublished. However, the basic work has been described in several publications [25-28]. As we received faecal specimens from only four of the 12 suspected cases in Nursery A, we had to use the suspected case status together with the confirmed case status for the epidemiological analyses, rather than the confirmed case status alone.

For Nursery B, we did not examine the animal faeces for EPEC 076 . The DNA profile of human and animal EHEC 026 isolates differed in one locus. When employing methods with large discriminatory power like MLVA, it is not unexpected for such small variations in DNA-profiles to occur within the short time frame of an outbreak. They reflect recent evolutionary divergence from a common ancestor, and do not preclude our conclusion regarding the source of infection. However, genotyping results must always be seen in context with the other results from the outbreak investigation.

\section{Conclusion}

The outbreaks affecting Nursery A and B were not part of the concomitant national outbreak of E. coli SF 0157 . This was an important finding, since the EHEC SF 0157 outbreak caused nine HUS cases of whom one died, and identification of the source was a major priority at the time. Furthermore, we concluded that the nursery outbreaks were caused by contact with animal faeces during the farm visits. This is only the third time an outbreak in Norway has been traced to animal contact.

\section{Recommendations}

Increased popularity of petting farms may lead to the occurrence of similar outbreaks in the future. Consequently, authorities in Norway as well as in other countries need to enforce hygienic measures when visiting farms with children. We did not advise the farms and nurseries described here to stop arranging farms visits with children, but we recommended letting only the oldest children enter the animal pens, and keeping them away from animals with diarrhoea, in addition to focusing on hand hygiene. Studies have reported that there is room for improvement concerning farm visitors' information on hygiene and hand washing in general [41-43]. To reduce human exposure to livestock faeces, several studies recommend a strict separation between picnic areas and animals, and to reinforce the importance of providing hand-washing facilities $[2,42]$. Previous findings suggest that active rather than passive interventions are more effective for increasing compliance [43].

The NIPH has published guidelines for farm visits with children [44]. In light of our findings, we recommend further efforts to spread and implement these guidelines among farmers and nursery staff.

\section{Acknowledgements}

We thank the staff of the two kindergartens for filling out the questionnaires, and chief medical officer of the municipality of Nannestad, Jan Erik Paulsen, for help in the investigation. We thank Viviane Bremer and Yvan Hutin at the European Programme of Intervention Epidemiology Training (EPIET), European Centre of Disease Prevention and Control, Stockholm, Sweden, for help in structuring the manuscript. We also thank Emily MacDonald at Department of Infectious Disease Epidemiology, the Norwegian Institute of Public Health, Oslo, Norway for help with the language aspect of the manuscript, and other employees at the department for help with the data handling and analysis.

References

1. Smith KE, Stenzel SA, Bender JB, Wagström E, Söderlund D, Leano FT, et al. Outbreaks of enteric infections caused by multiple pathogens associated with calves at a farm day camp. Pediatr Infect Dis J. 2004;23(12):1098-104.

2. Stirling J, Griffith M, Dooley JS, Goldsmith CE, Loughrey A, Lowery C), et al. Zoonoses associated with petting farms and open zoos. [Review] [37 refs]. Vector Borne Zoonotic Dis. 2008;8(1):85-92.

3. Heuvelink AE, van Heerwaarden C, Zwartkruis-Nahuis JT, van Oosterom R, Edink K, van Duynhoven YT, et al. Escherichia coli 0157 infection associated with a petting zoo. Epidemiol Infect. 2002;129(2):295-302.

4. Milne LM, Plom A, Strudley I, Pritchard GC, Crooks R, Hall M, et al. Escherichia coli $0_{157}$ incident associated with a farm open to members of the public. Commun Dis Publ Health. 1999;2(1):22-6.

5. Muto T, Matsumoto Y, Yamada M, Ishiguro Y, Kitazume H, Sasaki K, et al. Outbreaks of enterohemorrhagic Escherichia coli 0157 infections among children with animal contact at a dairy farm in Yokohama City, Japan. Jpn J Infect Dis. 2008;61(2):161-2.

6. Kassenborg HD, Hedberg CW, Hoekstra M, Evans MC, Chin $A E$, Marcus R, et al. Farm visits and undercooked hamburgers as major risk factors for sporadic Escherichia coli 0157: $\mathrm{H} 7$ infection: data from a case-control study in 5 FoodNet sites. Clin Infect Dis. 2004;38 Suppl 3:S271-8.

7. Payne CJ, Petrovic M, Roberts RJ, Paul A, Linnane E, Walker $M$, et al. Vero cytotoxin-producing Escherichia coli 0157 gastroenteritis in farm visitors, North Wales. Emerg Infect Dis. 2003;9(5):526-30.

8. Outbreaks of Escherichia coli $0157: \mathrm{H}_{7}$ infections among children associated with farm visits--Pennsylvania and Washington, 2000. Can Commun Dis Rep. 2001;27(14):117-20.

9. David ST, MacDougall L, Louie K, McIntyre L, Paccagnella AM, Schleicher S, et al. Petting zoo-associated Escherichia coli 0157:H7--secondary transmission, asymptomatic infection, and 
prolonged shedding in the classroom. Can Commun Dis Rep. 2004;30(20):173-80.

10. De Schrijver K, Buvens G, Posse B, Van den Branden D, Oosterlynck O, De Zutter L, et al. Outbreak of verocytotoxinproducing E. coli 0145 and 026 infections associated with the consumption of ice cream produced at a farm, Belgium, 2007. Euro Surveill. 2008;13(7):pii=8041. Available from: http:// www.eurosurveillance.org/ViewArticle.aspx?Articleld $=8041$

11. Parry SM, Salmon RL, Willshaw GA, Cheasty T, Lund LJ, Wearden P, et al. Haemorrhagic colitis in child after visit to farm visitor centre. Lancet. 1995;346(8974):572.

12. EpiNorth. EHEC infections caused by raw milk in Finland. Oslo: EpiNorth; 11 Oct 2012. Available from: http://www. epinorth.org/eway/default.aspx?pid $=230 \& \operatorname{trg}=$ Area 5340\&MainArea_5260=5340:0:15,3019:1:0:0:::0:0\&Ar ea_5340 $=5273: 47997:: 1: 5334: 5::: 0: 0$

13. Evans MR, Roberts RJ, Ribeiro CD, Gardner D, Kembrey D. A milk-borne Campylobacter outbreak following an educational farm visit. Epidemiol Infect. 1996;117(3):457-62.

14. Pollock KG, Locking ME, Beattie TJ, Maxwell H, Ramage I, Hughes D, et al. Sorbitol-fermenting Escherichia coli 0157 , Scotland. Emerg Infect Dis. 2010;16(5):881-2.

15. Tarr PI, Gordon CA, Chandler WL. Shiga-toxin-producing Escherichia coli and haemolytic uraemic syndrome. Lancet. 2005;365(9464):1073-86.

16. Alpers K, Werber D, Frank C, Koch J, Friedrich AW, Karch H, et al. Sorbitol-fermenting enterohaemorrhagic Escherichia coli $0157: \mathrm{H}$ - causes another outbreak of haemolytic uraemic syndrome in children. Epidemiol Infect. 2009;137(3):389-95.

17. Brandal LT, Løbersli I, Stavnes TL, Wester AL, Lindstedt BA. First report of shiga-toxin 1 in sorbitol-fermenting Escherichia coli 0157:H. J Clin Microbiol. 2012;50(5):1825-6.

18. Nygård K, Vold L, Heier BT, Bruun T, Kapperud G. Årsrapport: Matbårne infeksjoner og utbrudd i 2009. Meldingssystem for smittsomme sykdommer (MSIS) og vevbasert system for utbruddsvarsling (Vesuv) [Annual report: Foodborne infections and outbreaks in 2009. Reporting system for infectious diseases (MSIS) and web-based system for outbreak warning (Vesuv)]. Oslo: Norwegian Institute of Public Health; April 2010. Norwegian. Available from: http:// www.fhi.no/eway/default.aspx?pid $=233 \& \operatorname{trg}=$ MainLeft 5 583\&MainArea_5661=5583:0:15,1359:1:0:0:::0:0\&MainLe ft_5583=5603:84108::1:5699:58:::0:0\&4496=5699:2

19. Schimmer B, Nygard K, Eriksen HM, Lassen J, Lindstedt B-A, Brandal LT, et al. Outbreak of haemolytic uraemic syndrome in Norway caused by stx2-positive Escherichia coli $0_{103}: \mathrm{H}_{2} 5$ traced to cured mutton sausages. BMC Infect Dis. 2008;8:41.

20. Anbefalinger om når syke barnehagebarn bør holdes hjemme. Smittevernboken [Recommendations on when ill nursery children should be kept at home. The book of infectious disease control. Oslo: Norwegian Institute of Public Health. [Accessed 9 Nov 2012]. Norwegian. Available from: http:// www.fhi.no/eway/default.aspx?pid=233\&trg=MainLeft_6039\& MainArea_5661=6039:0:15,5077:1:0:0:::0:0\&MainLeft_6039=6 041:82617::1:6043:11:::0:0\#eHandbook826177

21. Oppklaring av utbrudd av næringsmiddelbårne sykdommer og zoonoser. Spørreskjema for bruk ved kohortundersøkelser av utbrudd [Investigation of outbreaks of food-borne diseases and zoonoses. Questionnaire for use in cohort studies of outbreaks] Oslo: Norwegian Institute of Public Health. [Accessed $19 \mathrm{Apr}$ 2012]. Norwegian. Available from: http:// www.fhi.no/eway/default.aspx?pid=233\&trg=MainArea_56618 MainArea_5661=5631:0:15,4643:1:0:0:::0:0

22. Combi-Strip, Rapid diagnostic test for in vitro detection of rotavirus and adenovirus in stool specimens. Gembloux: Coris BioConsep. [Accessed 16 Nov 2012]. Available from: http:// www.corisbio.com/Products/Human-Field/Rota-and-Adeno.php

23. ISO 10272-1:2006 Microbiology of food and animal feeding stuffs -- Horizontal method for detection and enumeration of Campylobacter spp. --Part 1: Detection method. Geneva: International Organization for Standardization (ISO); 17 Jun 2006. Available from: http://www.iso.org/iso/home/store/ catalogue_tc/catalogue_detail.htm?csnumber $=37091$

24. Urdahl AM, Cudjoe K, Wahl E, Heir E, Wasteson Y. Isolation of Shiga toxin-producing Escherichia coli $\mathrm{O}_{103}$ from sheep using automated immunomagnetic separation (AIMS) and AIMS ELISA: sheep as the source of a clinical E. coli $\mathrm{O}_{103}$ case? Lett Appl Microbiol. 2002;35(3):218-22.

25. Price EP, Smith H, Huygens F, Giffard PM. High-resolution DNA melt curve analysis of the clustered, regularly interspaced short-palindromic-repeat locus of Campylobacter jejuni. Appl Environ Microbiol. 2007;73(10):3431-6.

26. Schouls LM, Reulen S, Duim B, Wagenaar JA, Willems RJ, Dingle $\mathrm{KE}$, et al. Comparative genotyping of Campylobacter jejuni by amplified fragment length polymorphism, multilocus sequence typing, and short repeat sequencing: strain diversity, host range, and recombination. J Clin Microbiol. 2003;41(1):15-26.

27. Price EP, Thiruvenkataswamy V, Mickan L, Unicomb L, Rios RE, Huygens F, et al. Genotyping of Campylobacter jejuni using seven single-nucleotide polymorphisms in combination with flaA short variable region sequencing. J Med Microbiol. 2006;55(Pt8):1061-70.

28. Price EP, Huygens F, Giffard PM. Fingerprinting of Campylobacter jejuni by using resolution-optimized binary gene targets derived from comparative genome hybridization studies. Appl Environ Microbiol. 2006;72(12):7793-803.

29. Løbersli I, Haugum K, Lindstedt BA. Rapid and high resolution genotyping of all Escherichia coli serotypes using 10 genomic repeat-containing loci. J Microbiol Methods. 2012;88(1):134-9.

30. Lindstedt BA, Brandal LT, Aas L, Vardund T, Kapperud G. Study of polymorphic variable-number of tandem repeats loci in the ECOR collection and in a set of pathogenic Escherichia coli and Shigella isolates for use in a genotyping assay. J Microbiol Methods. 2007;69(1):197-205.

31. Sekse C, Sunde M, Lindstedt BA, Hopp P, Bruheim T, Cudjoe $\mathrm{KS}$, et al. Potentially human-pathogenic Escherichia coli 026 in Norwegian sheep flocks. Applied Environ Microbiol. 2011;77(14):4949-58

32. Brandal LT, Lindstedt BA, Aas L, Stavnes TL, Lassen J, Kapperud G. Octaplex PCR and fluorescence-based capillary electrophoresis for identification of human diarrheagenic Escherichia coli and Shigella spp. J Microbiol Methods. 2007;68(2):331-41.

33. Robertson L, Gjerde B, Forberg T, Haugejorden G, Kielland C. A small outbreak of human cryptosporidiosis associated with calves at a dairy farm in Norway. Scand J Infect Dis. 2006;38(9):810-3.

34. Rimseliene G, Vold L, Robertson L, Nelke C, Soli K, Johansen $\mathrm{OH}$, et al. An outbreak of gastroenteritis among schoolchildren staying in a wildlife reserve: thorough investigation reveals Norway's largest cryptosporidiosis outbreak. Scand J Publ Health. 2011;39(3):287-95.

35. Nygard K, Vold L, Lange H, Johansen $\mathrm{OH}$, Robertson L, Søli K, et al. Cryptosporidiosis outbreak among schoolchildren visiting a holiday farm in Norway. European Scientific Conference on Applied Infectious Disease Epidemiology (ESCAIDE); 24-26 Oct 2012; Edinburgh, UK.

36. Wahl E, Vold L, Lindstedt BA, Bruheim T, Afset JE. Investigation of an Escherichia coli 0145 outbreak in a child day-care centre - extensive sampling and characterization of eae- and stx1-positive E. coli yields epidemiological and socioeconomic insight. BMC Infect Dis. 2011;11:238.

37. European Food Safety Authority, European Centre for Disease Prevention and Control. The European Union summary report on trends and sources of zoonoses, zoonotic agents and food-borne outbreaks in 2009. EFSA Journal. 2011;9(3):2090. Available from: http://www.efsa.europa.eu/en/efsajournal/ doc/2090.pdf

38. Brandal LT, Sekse C, Lindstedt BA, Sunde M, Løbersli I, Urdahl $A M$, et al. Norwegian sheep is an important reservoir for human pathogenic Escherichia coli O26:H11. Appl Environ Microbiol. 2012;78(12):4083-91.

39. Patrick M, Schlundt J. Campylobacter enteritis. In: Heyman DL, ed. Control of Communicable Diseases Manual. 19 ed. Washington, DC: American Public Health Association; 2008. p. 94-8.

40. Fontaine O, Griffin P, Henao O, Lo Fo Wong D, Mintz E, Mody $R$, et al. Diarrhea, acute. In: Heyman DL, ed. Control of Communicable Diseases Manual. 19 ed. Washington, DC: American Public Health Association; 2008. p. 181-95.

41. Butikofer B, Bissig-Choisat B, Regula G, Corboz L, Wittwer M, Danuser J. [Incidence of zoonoses in petting zoos and evaluation of hygiene measures to prevent the transmission to humans]. German. Schweiz Arch Tierheilkd. 2005;147(12):532-40.

42. Heuvelink AE, Valkenburgh SM, Tilburg JJ, van Heerwaarden C, Zwartkruis-Nahuis JT, de Boer E. Public farms: hygiene and zoonotic agents. Epidemiol Infect. 2007;135(7):1174-83.

43. Anderson ME, Weese JS. Video observation of hand hygiene practices at a petting zoo and the impact of hand hygiene interventions. Epidemiol Infect. 2012;140(1):182-90.

44. Barn og gårdsbesøk [Children and farm visits]. Oslo: Norwegian Institute of Public Health. [Accessed 9 Nov 2012]. Norwegian. Available from: http://www.fhi.no/eway/default.as px?pid=233\&trg=MainLeft_5588\&MainArea_5661=5588:0:15,1 787:1:0:0:::0:0\&MainLeft_5588=5544:69375::1:5569:1:::0:0 